\title{
Perceived benefits, problems and risks in complementary and alternative medicine use among pregnant women in the Niger delta, Nigeria
}

\begin{abstract}
This study aim at identifying the perceived benefits, problems and risk associated with CAM use among pregnant women in the Niger Delta Region. The study engaged a crosssectional survey method and was conducted among 325 women in twelve communities. Data collected for the study were analysed using quantitative methods at the univariate, bivariate and multivariate level, and thematic content analysis for the qualitative data. Findings from the study showed that 'cultural belief' $(3.80 \pm 1.10)$, 'accessibility' (3.50 \pm 0.90$)$, 'meeting primary health needs' $(3.69 \pm 1.09)$ 'easy affordability' (3.30 \pm 1.18$)$, warding off evil spirit (3.08 \pm 1.132$)$, greater choices, control and participation (3.04 \pm 0.669$)$; and emphasis on prevention and wellness $(3.10 \pm 0.93)$ were all identified as the reasons for the use of CAM. On the other hand; 'lack of standardisation' $(3.21 \pm 0.957)$ 'lack of research institutes on CAM' (3.28 \pm 0.686$)$, 'safety and precautions about CAM use' (3.16 \pm 0.823$)$, 'too many quacks CAM practitioners' $(3.70 \pm 0.946)$ were all perceived as the risk involved in the use of CAM. Thus it is was recommended that as long as pregnant women continue to patronise the use of CAM, it is expedient that some form of regulation and standardisation be instituted by the government through the ministry of health at various levels.
\end{abstract}

Volume 9 Issue I - 2020

Endurance Uzobo

Department of Sociology, Niger Delta University, Nigeria

Correspondence: Endurance Uzobo, Department of Sociology, Niger Delta University, Wilberforce Island, Bayelsa State, Nigeria, Tel +2348065052298,

Email enduzobo@gmail.com

Received: October 14, 2019 | Published: January 14, 2020

Keywords: complementary and alternative medicine, pregnant women, perceived benefits, perceived problems, perceived risks

\section{Introduction}

The works of deBoer and Lamxay ${ }^{1}$ attributed the reasons for the use of CAM to be associated with traditional and cultural beliefs and practices as well as comparison of experiences between conventional health care professionals. Similarly, Ngubane cited in Mupfumira ${ }^{2}$ buttressing this point stated that in African culture, infants are particularly susceptible to harm from evil spirits and specific CAM are taken as a positive measure against bewitchment or to avoid misfortune as well as to ensure the baby's survival. Frenkel, BenArye, Carlson and Sierpina, ${ }^{3}$ in their study, opined that in Africa, many people use CAM to meet their primary health care needs because the therapy is easily accessible, and the only affordable source of health care in some countries, especially the world's most impoverished clients. Hence complementary and alternative medicine has gained recognition and has also become of great importance in the healthcare sector.

Furthermore, studies have also attributed the use of CAM by women to the perception that CAM is safe alternatives to conventional pharmaceuticals. ${ }^{4}$ A Canadian interview study by Westfall, ${ }^{5}$ on use of herb considered CAM to be safer than conventional pharmaceuticals because CAM was "milder", "more natural', "simpler", and "more familiar". Again, some studies have given the reasons of the use of CAM to include; Emphasis on prevention and wellness ${ }^{6}$, Emphasis on healing rather than cure, ${ }^{7}$ Non-invasive approach, ${ }^{8}$ Accessibility, ${ }^{9}, 10$ etc.

It is of great importance to note that studies have discussed the positive aspect of CAM; the negative aspect or risk involve hardly discussed in the literature. Some studies like that of the WHO, ${ }^{11}$ in highlighting the negative aspect of CAM stated that; there is a lack of common standards and understanding and appropriate methods for evaluating CAM to ensure safety, efficacy and quality control. This lack of standardization implies that one preparation of the same kind may be highly potent while another is ineffective. Hence, a single CAM product may be defined as food, a dietary supplement, or herbal medicine in different countries depending on the standards that apply to foods and medicines in each of those countries. In the same vein, preparation of an herbal product may use the flowers, leaves or stem, all of which vary in potency, and preparations may contain various concentrations of the actual herb versus carrier material. ${ }^{9}$ Also, some manufacturers may subject the herb to harsh chemical process that may lead to loss or reduction of their healthful properties. Different storage systems could also affect the potency of the remedies over time, whereas there are variations in strength according to soil in which they were grown or the season in which they were harvested. ${ }^{9}$ The lack of standardization as the WHO has shown is because of the lack of national policies on CAM. For instance, out of the 141 WHO member States, only $45(32 \%)$ countries have a national policy on CAM, ${ }^{10}$ In Africa, only 12 out of 46 countries have a national policy on CAM. Other problems involved in the use of CAM as stated by the $\mathrm{WHO}^{10}$ include; lack of laws and regulations, lack of national research institute on CAM. Other studies have identified safety and effectiveness ${ }^{12}$ inadequate training and certification, ${ }^{9}$ etc as the major problems with CAM.

Though the studies highlighted above have given the likely benefits and risks involved in the use of CAM, however, they were not conducted in the Niger Delta region of Nigeria which has different culture and practices from the settings of these other studies. Hence, this study, explore some of the issues raised by other studies and went a step further in addressing some other challenges and benefits 
that might likely influence the use of CAM in a different setting and location.

\section{Theoretical framework: theory of reasoned action and planned behaviour}

The Theory of reasoned action and the Theory of Planned Behaviour (TPB) was developed by Ajzen and Fishbein as an attempt to predict human behaviour. The Theory of Reasoned Action (TRA) and the Theory of Planned Behaviour (TPB) pay attention to the theoretical constructs concerned with individual motivational factors as determinants of the likelihood of exhibiting an explicit behaviour. TRA and TPB both accept that the best predictor of behaviour is behavioural intention, which in turn is determined by attitude toward the behaviour and social normative perceptions regarding it. TPB is an elongation of the TRA and includes an additional construct: perceived control over performance of the behaviour.

TRA model states that direct predictors of peoples' behavioural intention are their attitude toward accomplishing the behaviour and their subjective norm associated with the behaviour. The theory of planned behaviour went ahead further by adding perceived control over the behaviour, bearing in mind situations where one may not have complete volitional control over behaviour.

The TRA model went further to explain that attitude is determined by the individual's beliefs about outcomes or attributes of performing the behaviour (behavioral beliefs), weighted by evaluations of those outcomes or attributes. Consequently, if a person holds a strong belief which is positively treasured, the outcomes will result from performing the behaviour which will, in turn, have a positive attitude towards the behaviour. Alternatively, a person who holds a negative strong beliefs cherished outcome tends to have a negative attitude. ${ }^{13}$

Correspondingly, this model opined that a person's subjective norm is influenced by his or her normative beliefs, that is, if influential referent individuals support or condemn the performance of behaviour, compared by his or her motivation to conform to those members from the individual's referents. For instance, this theory proposed that if people believe in specific referents, they will perform behaviour, and hence, will be motivated to meet the expectations of those referents they hold positive subjective norms with. Conversely, someone who believes these referents belief should not perform the behaviour tends to have a negative subjective norm. Also, a person who is less motivated to comply with those referents is likely to have a relatively neutral subjective norm. ${ }^{13}$

TRA assumes that the most important direct influence of behaviour is the behavioral intention. Hence, success of explaining behaviour depends on the degree to which the behaviour is under volitional control (that is, individuals can exercise a large extent of control over the behaviour). It is not clear if the TRA components are adequate to predict behaviors in which volitional control is reduced. Thus, Ajzen included perceived behavioral control to reasoned action theory to elucidate predictors external to the individual's control which may affect his intentions and behaviors. With the addition of the perceived behavioral control, Ajzen and his colleagues created the Theory of Planned Behaviour (TPB).

The two theories admit a causal chain that connects behavioural beliefs, normative beliefs, and control beliefs to behavioural intentions and behaviours through attitudes, subjective norms, and perceived control. ${ }^{13}$
In applying these theories to this work, the belief and evaluation pregnant women have about the use of CAM eventually form their attitudes to the specific behaviour of using CAM. Furthermore, their normative belief about the use of CAM and specific motivations (e.g. from family and friends) forms their subjective belief about the use of CAM as being the most appropriate health outcome. The attitude to a specific use of CAM, Subjective norms of the use of CAM, and the perceived control over CAM leads to pregnant women's intention to use CAM and its future use.

\section{Material and methods}

This study was conducted among selected 361 pregnant women (325 Quantitative and 36 Qualitative) in fourteen selected communities in the South-South region of Nigeria. The choice of the selected communities was because they are in the upland areas of the Niger Delta region with an abundance of forest resources which the people mainly rely on for their daily health needs. The study also adopted both the quantitative and qualitative approach using a crosssectional survey design.

The study made use of mainly the purposive and snowball sampling technique in its quest to get respondents for the study. First, the study purposely selected communities with maternity centres where women go for antenatal services. This was because it is at these centres that a considerable chunk of the respondents could be found. The purposive sampling technique was further used to select women who were less than eight months pregnant. This was done in order not to disturb those pregnant women who were very close to putting to bed as the matrons of these maternity centres advice. Finally, the snowball sampling technique was used to locate pregnant women who do not attend maternity centres to capture their experience in their natural environment and to observe the CAM they were currently using.

Data for this study was collected using the questionnaire and an indepth interview instrument with the assistance of four female research assistants. While most women in the maternity centres were given the questionnaire to fill, those sampled at home were interviewed. Each pregnant woman was interviewed separately. Before the interviews, participants were informed of the aims and the major themes of the study. The interviews pattern was similar to a conversation, where respondents could respond freely to questions. In cases where respondents do not have formal education and cannot express themselves adequately using the English language, the interviews were conducted in the local dialects of the respondents or the use of Pidgin English. The questionnaires, on the other hand, were filled with the help of the research assistants.

On average, the interview with each participant lasted for approximately 40-50minutes, while the questionnaires took approximately 20 minutes to complete. Everyone that participated in the study were assigned pseudo names which were used for data analysis. However, the location and occupation of the members interviewed were real in if the respondents agree to it. Data generated from the qualitative instruments were analyzed based on three levels: uni variate, bivariate and multivariate analysis for the quantitative data using the SPSS. Hence, percentages, tables and charts were used for uni variate analysis, chi-square cross tabulations for bivariate and multiple regression for multivariate. Qualitative data, on the other hand, were analyzed following the steps outlined by Burnard for thematic content analysis through the aid of the NVivo 10 . 
In order to maintain a high ethical standard during the study, this research was presented before the department of sociology research committee of the Niger Delta University who approved the study. Also, the study was approved by the Bayelsa State Health Research Ethics Committee of the Ministry of Health, and ethical clearance certificate granted with approval number: BSHREC/Vol.1/18/119. Permission was also sought from the heads of communities of the study area involved according to their gate-keeping policy. Also, verbal approval was given by the matrons of the maternity centres after presenting the approval letter from the department of sociology. After obtaining approval from the gate-keepers, the consent of individual participants was also sought before they were enrolled for the study.

\section{Results}

\section{Socio-demographic characteristics of the respondents by sub-groups}

This section of data analysis shows the result of the sociodemographic variables by linguistic groups where each linguistic group is cross-tabulated with age, marital status, education, religion, type of family, occupation, nature of the job, employment type, average income per month, number of pregnancies and household status. The overall mean age were 30.95 and a standard deviation of 5.640 ranging from 15-44years. The results of the socio-demographic characteristics of the respondents are presented in (Table 1). Based on the analysis, all socio-demographic variables except religion (0.142) and types of families $(0.129)$ were found to be significantly related to linguistic group at $\mathrm{p}<0.05$.

As the table revealed, there were more respondents $(38.2 \%)$ from Anyama clan, followed by respondents from Oloibiri $(28 \%)$. Respondents from Kolo clan constituted 17.2per cent, while Abureni $(8 \%)$ and Kugbo clan (8.6\%) respectively. Anyama and Oloibiri clan having the highest number of respondents are not unconnected with the fact that more communities were sampled from these clans.

(Table 1) further revealed that there is a positive association between respondents' clan and their age $(\mathrm{P}=0.000)$. A close examination of the ages of respondent's shows explicitly that majority of the respondents in the study were between the ages of 30-34 (33.2\%). The second highest age of the respondents is those between the ages of $25-29(22.7 \%)$. Another age category with a significant number of respondents is those between the ages of 35-39 (19.9\%). From table 1 again, the study showed that respondents between the ages of 2024 (12.9\%), 40-44 (5.8\%) and 15-19 (5.3\%), had the least numbers of respondents. Therefore, it is convenient to state at this junction that, age is associated with fertility rate. This is to state that women between the ages 25-39 are more productive than women between the ages of 15-24 and 40-45. In terms of the marital status of the respondents, table 1 also found out that marital status was significant by clans $(\mathrm{P}<0.000)$. Specifically, more than half of the pregnant women $(51.1 \%)$ have remained married. A significant percentage of pregnant women $(33.3 \%)$ stated that they were cohabiting. Only a few numbers of the respondents were either still single (never married) $[8.2 \%]$ or divorced/separated $(7.6 \%)$.

Table I Distribution of Respondents by Socio-Demographic Variables and Linguistic Group ( $n=325, \%=100)$

\begin{tabular}{|c|c|c|c|c|c|c|c|c|c|}
\hline \multirow[b]{2}{*}{$\begin{array}{l}\text { Demographic } \\
\text { variables }\end{array}$} & \multicolumn{5}{|c|}{ Linguistic-groups in ogbia } & \multirow[b]{2}{*}{$\begin{array}{l}\text { Total } \\
\mathbf{N}(\%)\end{array}$} & \multirow[b]{2}{*}{$\mathbf{X}^{2}$} & \multirow[b]{2}{*}{ DF } & \multirow[b]{2}{*}{ Pvalue } \\
\hline & $\begin{array}{l}\text { Oloibiri } \\
(n=91, \\
=28.0)\end{array}$ & $\begin{array}{l}\text { Kolo } \\
(n=56, \\
\%=\mid 7.2)\end{array}$ & $\begin{array}{l}\text { Anyama } \\
(n=124, \\
\%=38.2)\end{array}$ & $\begin{array}{l}\text { Abureni } \\
(n=26, \\
\%=8.0)\end{array}$ & $\begin{array}{l}\text { Kugbo } \\
(n=28, \\
\%=8.6)\end{array}$ & & & & \\
\hline \multicolumn{10}{|l|}{ Age } \\
\hline $15-19$ & $3(0.9 \%)$ & $4(1.2 \%)$ & $3(0.9 \%)$ & $3(0.9 \%)$ & $4(1.2 \%)$ & $17(5.2 \%)$ & & & \\
\hline $20-24$ & $10(3.1 \%)$ & $9(2.8 \%)$ & $16(4.9 \%)$ & $5(1.5 \%)$ & $2(0.6 \%)$ & $42(12.9 \%)$ & & & \\
\hline $30-34$ & $31(9.5 \%)$ & $24(7.4 \%)$ & $39(12.0 \%)$ & $4(1.2 \%)$ & $10(3.1 \%)$ & $108(32.2)$ & & & \\
\hline $35-39$ & $19(5.8 \%)$ & $2(0.6 \%)$ & $37(11.4 \%)$ & $2(0.6 \%)$ & $5(1.5 \%)$ & $65(20 \%)$ & 48.57 & 20 & 0.000 \\
\hline $40-44$ & $9(2.8 \%)$ & $6(1.8 \%)$ & $2(0.6 \%)$ & $0(0.0 \%)$ & $2(0.6 \%)$ & $19(5.8 \%)$ & & & \\
\hline \multicolumn{10}{|l|}{ Marital Status } \\
\hline Ever Married & $63(19.4 \%)$ & $29(8.9 \%)$ & $47(14.5 \%)$ & |4(4.3\%) & $13(4.0 \%)$ & $166(51.1 \%)$ & & & \\
\hline Never Married & $5(1.5 \%)$ & $5(1.5 \%)$ & $7(2.2 \%)$ & $5(1.5 \%)$ & $5(1.5 \%)$ & $27(8.3 \%)$ & & & \\
\hline Divorced/Sep. & $3(0.9 \%)$ & $8(2.5 \%)$ & $7(2.2 \%)$ & $4(1.2 \%)$ & $2(0.6 \%)$ & $24(7.4 \%)$ & 47.44 & 12 & 0.000 \\
\hline \multicolumn{10}{|l|}{ Education } \\
\hline No formal education & $2(0.6 \%)$ & $3(0.9 \%)$ & $5(1.5 \%)$ & $2(0.6 \%)$ & $2(0.6 \%)$ & $14(4.3 \%)$ & & & \\
\hline Primary education & |4(4.3\%) & $7(2.2 \%)$ & $8(2.5 \%)$ & $4(1.2 \%)$ & $\mathrm{I}(0.3 \%)$ & $34(105 \%)$ & & & \\
\hline Secondary education & $32(9.8 \%)$ & $28(8.6 \%)$ & $87(26.8 \%)$ & $12(3.7 \%)$ & $14(4.3 \%)$ & $173(53.2 \%)$ & 4973 & 16 & חמחת \\
\hline Technical education & $3(0.9 \%)$ & $8(2.5 \%)$ & $7(2.2 \%)$ & $2(0.6 \%)$ & $3(0.9 \%)$ & $23(7.1 \%)$ & 48.13 & 16 & 0.000 \\
\hline Tertiary education & $40(12.3 \%)$ & $10(3.1 \%)$ & $17(5.2 \%)$ & $6(1.8 \%)$ & $8(2.5 \%)$ & $81(24.9 \%)$ & & & \\
\hline \multicolumn{10}{|l|}{ Religion } \\
\hline Christianity & $85(26.2 \%)$ & $52(16.0 \%)$ & II7(36.0\%) & $24(7.4 \%)$ & $27(8.3 \%)$ & $305(93.8 \%)$ & & & \\
\hline Islam & $0(0.0 \%)$ & $0(0.0 \%)$ & $0(0.0 \%)$ & $\mathrm{I}(0.3 \%)$ & $0(0.0 \%)$ & $\mathrm{I}(0.3 \%)$ & 12.22 & 8 & 0.142 \\
\hline Traditional Religion & $6(1.8 \%)$ & $4(1.2 \%)$ & $7(2.2 \%)$ & $\mathrm{I}(0.3 \%)$ & $\mathrm{I}(0.3 \%)$ & $19(5.8 \%)$ & & & \\
\hline
\end{tabular}


Table Continued

\begin{tabular}{|c|c|c|c|c|c|c|c|c|c|}
\hline \multirow{2}{*}{$\begin{array}{l}\text { Demographic } \\
\text { variables }\end{array}$} & \multicolumn{5}{|c|}{ Linguistic-groups in ogbia } & \multirow{2}{*}{$\begin{array}{l}\text { Total } \\
\mathbf{N}(\%)\end{array}$} & \multirow[b]{2}{*}{$\mathbf{X}^{2}$} & \multirow[b]{2}{*}{ DF } & \multirow[b]{2}{*}{ Pvalue } \\
\hline & $\begin{array}{l}\text { Oloibiri } \\
(n=91, \\
=28.0)\end{array}$ & $\begin{array}{l}\text { Kolo } \\
(n=56, \\
\%=\mid 7.2)\end{array}$ & $\begin{array}{l}\text { Anyama } \\
(n=124, \\
\%=38.2)\end{array}$ & $\begin{array}{l}\text { Abureni } \\
(n=26, \\
\%=8.0)\end{array}$ & $\begin{array}{l}\text { Kugbo } \\
(n=28, \\
\%=8.6)\end{array}$ & & & & \\
\hline \multicolumn{10}{|l|}{ Types of family } \\
\hline Monogamous & $74(22.8 \%)$ & $40(12.3 \%)$ & $106(32.7 \%)$ & $2 \mathrm{I}(6.5 \%)$ & $2 \mathrm{I}(6.5 \%)$ & $262(80.9 \%)$ & \multirow{3}{*}{12.54} & \multirow{3}{*}{8} & \multirow{3}{*}{0.129} \\
\hline polygamous & $\mathrm{II}(3.4 \%)$ & $7(2.2 \%)$ & $14(4.3 \%)$ & $3(0.9 \%)$ & $5(1.5 \%)$ & $4 I(12.6 \%)$ & & & \\
\hline Single parenthood & $6(1.9 \%)$ & $9(2.8 \%)$ & $2(0.6 \%)$ & $2(0.6 \%)$ & $2(0.6 \%)$ & $22(6.8 \%)$ & & & \\
\hline \multicolumn{10}{|l|}{ Occupation } \\
\hline Farming & $9(2.8 \%)$ & $12(3.7 \%)$ & $2 \mathrm{I}(6.5 \%)$ & $8(2.5 \%)$ & $4(1.2 \%)$ & $54(16.6 \%)$ & \multirow{7}{*}{123.81} & \multirow{7}{*}{24} & \multirow{7}{*}{0.000} \\
\hline Fishing & $0(0.0 \%)$ & $4(1.2 \%)$ & $9(2.8 \%)$ & $8(2.5 \%)$ & $\mathrm{I}(0.3 \%)$ & $22(6.8 \%)$ & & & \\
\hline Civil servant & $19(5.8 \%)$ & $12(3.7 \%)$ & $4(1.2 \%)$ & $2(0.6 \%)$ & $6(1.8 \%)$ & $43(13.2 \%)$ & & & \\
\hline Small scale business & $4 I(12.6 \%)$ & $20(6.2 \%)$ & $20(6.2 \%)$ & $0(0.0 \%)$ & $4(1.2 \%)$ & $85(26.2 \%$ & & & \\
\hline Student & $2(0.6 \%)$ & $5(1.5 \%)$ & $30(9.2 \%)$ & $2(0.6 \%)$ & $8(2.5 \%)$ & $47(14.5 \%)$ & & & \\
\hline Currently not in any & $6(1.8 \%)$ & $3(0.9 \%)$ & $7(2.2 \%)$ & $0(0.0 \%)$ & $0(0.0 \%)$ & $16 .(4.9 \%)$ & & & \\
\hline Others & $14(4.3 \%)$ & $0(0.0 \%)$ & $33(10.2 \%)$ & $6(1.8 \%)$ & $5(1.5 \%)$ & $58(17.8 \%)$ & & & \\
\hline \multicolumn{10}{|l|}{ Average Income } \\
\hline N5,000 & $7(2.2 \%)$ & $7(2.2 \%)$ & $40(12.4 \%)$ & $2(0.6 \%)$ & $2(0.6 \%)$ & $58(18.0 \%)$ & & & \\
\hline N 5,000 - N15,999 & $54(16.7 \%)$ & $15(4.6 \%)$ & $23(7.1 \%)$ & $4(1.2 \%)$ & II (3.4\%) & $107(33.1 \%)$ & \multirow{4}{*}{96.45} & \multirow{4}{*}{16} & \multirow{4}{*}{0.000} \\
\hline NI6,000-N25,999 & $9(2.8 \%)$ & $12(3.7 \%)$ & $17(5.3 \%)$ & $15(4.6 \%)$ & $4(1.2 \%)$ & $57(17.6 \%)$ & & & \\
\hline$A 26,000-A 35,999$ & $8(2.5 \%)$ & $8(2.5 \%)$ & $7(2.2 \%)$ & $3(0.9 \%)$ & $5(1.5 \%)$ & $31(9.6 \%)$ & & & \\
\hline $\mathrm{N} 36,000$ and above & $13(4.0 \%)$ & $12(3.7 \%)$ & $37(11.5 \%)$ & $2(0.6 \%)$ & $6(1.9 \%)$ & $72(22.2 \%)$ & & & \\
\hline \multicolumn{10}{|l|}{ Number of times } \\
\hline pregnant & $5(1.5 \%)$ & $15(4.6 \%)$ & $54(16.6 \%)$ & $22(6.8 \%)$ & $9(2.8 \%)$ & $105(32.3 \%)$ & \multirow{5}{*}{121.30} & \multirow{5}{*}{16} & \multirow{5}{*}{0.000} \\
\hline 1 & $4(4.3 \%)$ & $9(2.8 \%)$ & $37(11.4 \%)$ & $0(0.0 \%)$ & $3(0.9 \%)$ & $63(19.4 \%)$ & & & \\
\hline $\begin{array}{l}2 \\
2\end{array}$ & $12(3.7 \%)$ & $14(4.3 \%)$ & $10(3.1 \%)$ & $0(0.0 \%)$ & $4(1.2 \%)$ & $40(12.3 \%)$ & & & \\
\hline 3 & $42(12.9 \%)$ & $6(1.8 \%)$ & $12(3.7 \%)$ & $2(0.6 \%)$ & $7(2.2 \%)$ & $69(21.2 \%)$ & & & \\
\hline $\begin{array}{l}4 \\
\text { 5and above }\end{array}$ & $18(5.5 \%)$ & $12(3.7 \%)$ & $\mathrm{II}(3.4 \%)$ & $2(0.6 \%)$ & $5(1.5 \%)$ & $48(14.8 \%)$ & & & \\
\hline \multicolumn{10}{|l|}{ Household status } \\
\hline Head of the house & $2(0.6 \%)$ & $2(0.6 \%)$ & $0(0.0 \%)$ & $2(0.6 \%)$ & $0(0.0 \%)$ & $6(1.9 \%)$ & \multirow{4}{*}{101.61} & \multirow{4}{*}{12} & \multirow{4}{*}{0.000} \\
\hline Proxy to head & $85(26.4 \%)$ & $39(12.1 \%)$ & $73(22.7 \%)$ & $20.6(\%)$ & $18(5.6 \%)$ & $217(67.4 \%)$ & & & \\
\hline Not head of the house & $3(0.9 \%)$ & $10(3.1 \%)$ & $5 \mathrm{I}(15.8 \%)$ & $22(6.8 \%)$ & $9(2.8 \%)$ & $95(29.5)$ & & & \\
\hline $\begin{array}{l}\text { Distant relationship to } \\
\text { the head }\end{array}$ & $0(0.0 \%)$ & $3(0.9 \%)$ & $0(0.0 \%)$ & $0(0.0 \%)$ & $\mathrm{I}(0.3 \%)$ & $4(1.2 \%)$ & & & \\
\hline
\end{tabular}

Also, there is a positive relationship between educational status and the clans of respondents $(\mathrm{P}=0.000)$. More than half the respondents (53.2\%) have had secondary education. Again, 24.9per cent of the respondents claimed to have acquired tertiary education. No formal education (4.2\%), Primary education (10.5) and technical education $(7.1 \%)$ had the least number of respondents respectively. An Overwhelming number of the respondents (93.7\%) claimed to be religiously affiliated to Christianity.

Additionally, based on type of families, (Table 1) revealed that there is no significant relationship between types of family and the clans of the respondents $(p<0.142)$. A breakdown of the types of family by clans revealed that most of the respondents $(80.8 \%)$ were in monogamous families. More so, 12.3per cent of the respondents were in polygamous families. Finally, only 6.5 percent of the respondents were from single parents' families. Based on this analysis, we can infer that respondents in the area of study practice more of monogamous marriages. The disparity in monogamous polygynous, and singleparents' unions echoes a gradual decline of polygyny in Nigeria which may be as a result of the incursion of modernisation and globalisation.
Further analysis of the occupational status of the respondents in "(Table 1) shows that respondents' occupation is significantly related to the clans of the respondents $(\mathrm{p}>0.01)$. Analysis of the types of occupations indicates that the highest number the respondents were engaged in small-scale businesses $(26.2 \%)$. Other categories of occupation as identified by the respondents include; Farming (16.6\%), Civil service (13.1\%), Fishing (6.8\%), Students (14.5\%), not currently in any occupation $(4.9 \%)$ and others $(17.8 \%)$. The fact that most respondents are engaged in small-scale business and civil service attest to the fact that Agricultural activities are fast occupying the back seat even in rural societies, which is further aggravated by persistent pollution and degradation of the Niger Delta environment. Hence, most people have taken up small scale business as an alternative.

The average income of respondents showed that those earning between $\$ 5,000-\$ 15,999(33.1 \%)$ formed the highest number of respondents. The second highest income earners were those who earn between $\$ 36,000$ and above(22.2\%). The other categories of income earners were those that earned less than $\$ 5,000(18.0 \%$ ), those that earn between $\$ 16,000$ - $\$ 25,999$ (17.6\%), and those that earn between 


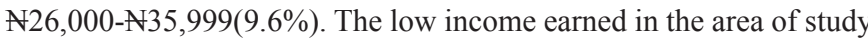
might be attributed to the fact that the respondents are women engaged in low-income occupations like trading and Agricultural activities, coupled with the low level of education.

In respect to the number of times respondents have been pregnant, the analysis showed that association still exist between the number of pregnancies and clans $(\mathrm{p}>0.000)$. Further analysis revealed that a higher number of respondents $(32.3 \%)$ stated that their current pregnancy was the first one. The second-highest categories were respondents who indicated that they were currently pregnant with their fourth child $(21.2 \%)$. The third highest category was respondents who claimed that their current pregnancy was their second. Those who indicated that their current pregnancy was their third were 12.3 per cent of the respondents, while those who stated that it was their fifth and above were 14.8percent. Though, this finding shows a fertility decline, respondents with three and above pregnancies are still high indicating a high fertility rate within the region.

Finally, an association also exist between the household status of the respondents and their clans $(\mathrm{p}<0.000)$. From table 1, majority of the respondents were those that were close to the head of their household (67.4\%). 29.5percent of the respondents indicated that they were not close to the head of their household. Only 1.9 and 1.4 per cent of the respondents were head of their households and had a distant relationship with the heads of their households respectively. This finding might be as a result of the fact that in most traditional settings especially in Africa, women are still subject to the rule of men even if she is single, divorced or separated.

\section{Perceived reasons/benefits of using CAM}

This section of the study is concerned with the reasons/benefits and dangers of using CAM. Indeed, it examined the various factors that influence the use of CAM among pregnant women. Respondents were asked the reasons why they use CAM, as shown by (Table $2)$, the mean score for 'cultural belief' $(3.80 \pm 1.10)$ showed that respondents quite agreed that 'cultural belief' was one of the reasons for the use of CAM. Another reason identified by the respondents was 'accessibility' with a score of $3.50 \pm 0.90$. This also implies that majority of the respondents agreed that CAMs are more accessible than other healthcare systems. For this reason, it is preferable to use CAM than other medical options.

Besides, 'meeting primary health needs' with a mean score of $3.69 \pm 1.09$ indicates that majority of the respondents agreed with the fact that CAMs are used because it meets the primary health needs of the users when compared to other methods of healthcare services. Similarly, 'easy affordability' (3.30 \pm 1.18$)$; warding off evil spirit (3.08 \pm 1.132$)$; greater choices, control and participation (3.04 \pm 0.669$)$; and emphasis on prevention and wellness $(3.10 \pm 0.93)$ were also identified by the majority of the respondents as the reasons for the use of CAM. Nonetheless, while majority of the respondents agreed that the aforementioned reasons influence their use of CAM, 'safe alternative to conventional medicine' $(2.85 \pm 0.884)$; 'more effective way of promoting health' $(2.79 \pm 0.731)$ and 'emphasis on healing rather than cure' $(2.74 \pm 0.84)$ were not accepted as the reasons for the use of CAM by majority of the respondents. This means that there are significant differences in the reasons for the use of CAM by the respondents.

Table 2 Distribution of the respondents by the reasons for CAM use (N=325)

\begin{tabular}{|c|c|c|c|c|c|c|c|}
\hline \multirow{2}{*}{ Reasons } & \multicolumn{7}{|c|}{ 5-point Likert scale distribution } \\
\hline & $\begin{array}{l}\text { Strongly } \\
\text { Disagree (\%) }\end{array}$ & Disagree(\%) & $\begin{array}{l}\text { Somewhat } \\
\text { Agree (\%) }\end{array}$ & $\begin{array}{l}\text { Agree } \\
(\%)\end{array}$ & $\begin{array}{l}\text { Strongly } \\
\text { Agree (\%) }\end{array}$ & $\begin{array}{l}\text { Mean } \\
\text { (Std. dev) }\end{array}$ & $\begin{array}{l}\text { Research } \\
\text { Decision }\end{array}$ \\
\hline Cultural belief & $14(6.3)$ & $2(0.9)$ & 71 (32.7) & $65(29.0)$ & $72(32.1)$ & $3.80(1.096)$ & Accept \\
\hline Easily accessible & $14(6.3)$ & $4(1.8)$ & $60(26.8)$ & $\begin{array}{l}129 \\
(57.6)\end{array}$ & $17(7.6)$ & $3.58(0.899)$ & Accept \\
\hline Meeting primary health needs & $10(5.2)$ & $6(3.1)$ & $61(31.6)$ & $73(37.8)$ & $43(22.3)$ & 3.69 (1.019) & Accept \\
\hline Easily affordable & $35(15.6)$ & $8(3.6)$ & $54(24.1)$ & $\begin{array}{l}108 \\
(48.2)\end{array}$ & $19(8.5)$ & $3.30(1.182)$ & Accept \\
\hline $\begin{array}{l}\text { Warding off evil spirits and } \\
\text { witches }\end{array}$ & $33(15.0)$ & $21(9.5)$ & $73(33.2)$ & $81(36.8)$ & $12(5.5)$ & $3.08(1.132)$ & Accept \\
\hline $\begin{array}{l}\text { Safe alternative to } \\
\text { conventional medicine }\end{array}$ & $12(6.3)$ & $52(27.2)$ & $83(43.5)$ & $4 \mid(2 I .5)$ & $3(1.6)$ & $2.85(0.884)$ & Reject \\
\hline $\begin{array}{l}\text { More effective way of } \\
\text { promoting health }\end{array}$ & $8(4.2)$ & $49(25.7)$ & III (58.I) & $2 I(11.0)$ & $2(1.0)$ & $2.79(0.731)$ & Reject \\
\hline $\begin{array}{l}\text { Greater choices, control and } \\
\text { participation }\end{array}$ & $6(3.1)$ & $20(10.3)$ & $132(67.7)$ & 35 (I7.9) & $2(1.0)$ & $3.04(0.669)$ & Accept \\
\hline $\begin{array}{l}\text { Emphasis on prevention and } \\
\text { wellness }\end{array}$ & $6(3.0)$ & $43(2 \mid .8)$ & $87(44.2)$ & 47 (23.9) & $14(7.1)$ & $3.10(0.926)$ & Accept \\
\hline $\begin{array}{l}\text { Emphasis on healing rather } \\
\text { than cure }\end{array}$ & $14(7.2)$ & $53(27.2)$ & $104(53.3)$ & $18(9.2)$ & $6(3.1)$ & $2.74(0.842)$ & Reject \\
\hline
\end{tabular}


Other reasons for the use of CAM are reported in (Table 3). Respondents were asked whether they have health centres in their respective communities. There is existence of significant association between other reasons for the use of CAM and sub-clans $\left(\mathrm{X}^{2}=56.194\right.$, $\mathrm{p}<0.05$ ). The table further shows that nearly all the respondents across all clans indicated that they have health centres. This implies that at least there is one health centre located within the communities across the sub-clans. However, the availability of health centres may not necessarily mean they were functional. This study found that while majority of respondents in some clans said they have functional health centres, others did not agree that those health centres were functional. The challenges of the health centres were further ascertained. A large proportion of the respondents in Oloibiri (100.0\%), Agholo (47.5\%), Anyama (67.9\%), Abureni (100.0\%) and Kugbo (78.3\%) attributed their challenges to "lack of competent health professionals in those health centres. Others reported that their services were unaffordable. This may affect the likelihood of effective utilisation of the health centres and influence the use of CAM in the areas.

Table 3 Distribution of respondents by other reasons for the use of CAM $(n=325)$

\begin{tabular}{|c|c|c|c|c|c|c|c|}
\hline \multirow[b]{2}{*}{ Other reasons for CAM use } & \multicolumn{7}{|l|}{ Sub-Clans } \\
\hline & $\begin{array}{l}\text { Oloibiri } \\
(n=91)\end{array}$ & $\begin{array}{l}\text { Agholo } \\
\text { (kolo) }(n=56)\end{array}$ & $\begin{array}{l}\text { Anyama } \\
(n=124)\end{array}$ & $\begin{array}{l}\text { Aburemi } \\
(n=26)\end{array}$ & $\begin{array}{l}\text { Kugbo } \\
(n=28)\end{array}$ & $\mathbf{X}^{2}$ & p-value \\
\hline \multicolumn{8}{|l|}{ Availability of health centres } \\
\hline Yes & $78(85.7)$ & $50(92.6)$ & $49(50.0)$ & $26(100.0)$ & $19(67.9)$ & \multirow{2}{*}{56.194} & \multirow{2}{*}{0.000} \\
\hline No & $13(14.3)$ & $4(7.4)$ & $49(50.0)$ & $0(0.0)$ & $9(32.1)$ & & \\
\hline \multicolumn{8}{|l|}{ Functional health centres } \\
\hline Yes & $75(82.4)$ & 48 (88.9) & $48(65.8)$ & $26(36.5)$ & $16(61.5)$ & \multirow{3}{*}{34.077} & \multirow{3}{*}{0.000} \\
\hline No & $13(14.3)$ & $2(3.7)$ & $2(32.9)$ & $0(0.0)$ & $9(34.6)$ & & \\
\hline Not sure & $3(3.3)$ & $4(7.4)$ & I (I.4) & $0(0.0)$ & I (3.8) & & \\
\hline \multicolumn{8}{|l|}{ Challenges of health centres } \\
\hline Not accessible & $0(0.0)$ & - & - & - & - & \multirow[b]{3}{*}{40.616} & \multirow[b]{3}{*}{0.000} \\
\hline Not affordable & $0(0.0)$ & $19(47.5)$ & $18(32.1)$ & $0(0.0)$ & $5(2 \mid .7)$ & & \\
\hline Medicine are not effective & $0(0.0)$ & $2(5.0)$ & $0(0.0)$ & $0(0.0)$ & $0(0.0)$ & & \\
\hline Lack of competent health professionals & $53(100.0)$ & $19(47.5)$ & $38(67.9)$ & $4(100.0)$ & $18(78.3)$ & & \\
\hline \multicolumn{8}{|l|}{ Place of seeking for medical help } \\
\hline Health centre & $46(54.8)$ & $26(48.1)$ & $77(62.1)$ & $4(15.4)$ & $14(50.0)$ & & \\
\hline Traditional medicine men & $22(26.2)$ & $24(44.4)$ & $42(33.9)$ & $0(0.0)$ & $7(25.0)$ & \multirow{3}{*}{137.415} & \multirow{3}{*}{0.000} \\
\hline Use CAM at home & I (I.2) & $4(7.4)$ & $0(0.0)$ & $0(0.0)$ & $0(0.0)$ & & \\
\hline Others & 15 (I7.9) & $0(0.0)$ & $5(4.0)$ & $22(84.6)$ & $7(25.0)$ & & \\
\hline
\end{tabular}

$\mathrm{X}^{2}=$ Chi Square

$\mathrm{Df}=$ degree of freedom

CAM=complementary/alternative medicine

The table added the places to which respondents sought medical help. It was found that at least one-half of the respondents from Oloibiri $(54.8 \%)$, Anyama (62.1\%) and Kugbo (50.0\%) sought medical help from the health centres, while others resort to traditional medicine men or use CAM at home. This is indicative that while most pregnant women utilised the modern healthcare facilities, they still complement it with the use of CAM in their areas based on the reasons highlighted above.

From the qualitative responses to the reasons for the use of CAM, different reasons were mentioned by the participants. As this participant from Otuoke highlighted, cultural belief, inheritance and physical benefits are the reasons why she is using CAM, rather than the cost. In her statement: The reasons why I use CAM are because of my cultural belief. Because my mother has been making use of CAM and all her children were delivered safely without the help of medical doctors. It is not because I do not have money to afford conventional drugs, because I registered with the health centre with N2, 000 and still buy drugs from them. These CAM products have been found useful during my mother's time, and they are always easily found. Also, I go to church for prayers because of protection for me and my baby. The primary physical health benefits I derived from using CAM are:

a. The tightness of my stomach was relieved after sprinkling alligator pepper and the dried palm fronds on my stomach.

b. The bitter kola stopped the cough and spitting

c. The local herbs which I drank help to ease body pain.

d. The massaging made the baby to be placed correctly in the stomach which eases safe delivery.

e. The mixture of boiled water lily and kaikai (local gin), which I drank helped relieved pain.

f. The hydraulics mixed with red native chalk calms the sweety (rashes) on my body. 


\section{(IDI/otuoke/oloibiri/20|8)}

In line with the participant above, another participant further discussed that she is using CAM particularly massaging in order to avoid complications on the day of delivery as well as because she inherited the practice from her parent, and not because of the cost of their health services. As she added, CAM use is more efficacious than orthodox medicine. As she narrated: "I use CAM because I believe that it is essential for my baby and me. For instance, if I do not go for massage there might be complications on the day of delivery. Also, my mother advised me to patronise CAM products which worked for her. Again, not because of lack of money but, the CAM works better than the drugs given in the health centre. I have experienced enormous physical health benefits from using CAM. These include;

a) When I complained of cough and catarrh to the doctor in the health centre drugs were prescribed for me, which didn't stop the cough and catarrh, but after applying Amabhuo in my nostril for few days the catarrh \& cough stopped, and when I chewed bitter kola and alligator pepper, it reduced the rate of my vomiting and spitting.

b) In the health centre, they don't care about the position of your baby, they only give you advice on how to stay as a pregnant woman, but the people that massage always make sure that the baby is in a proper position massaging has helped my baby kick well, I can feel that my baby is alive" (IDI/Otuasega/Agholo Clan/2018)

Another participant also explained that the benefits she derived from the use of CAM were associated with its costs and efficacy. Put differently, the cost of using CAMs is less than that of conventional medicine as well as more efficacious when compared to orthodox medicine. As she explained: I use CAM because my great grandmother has been using it and delivered safely. All my elder sisters have used it, and they all delivered their babies safely. Also, I do not have money to register with the health centre. I also believe that God has given us everything we need to take care of ourselves when pregnant, so there is no need to go to the hospital. Again, the woman that massages me has been massaging my elder sister for long, and the herbs have been useful. I have benefited from using CAM because all the plant products I took cured what they were used for. These ranged from 'hospital too far' and milk that enabled my blood level to increase because after some days I was no longer looking pale like before; lemongrass boiled with tombo relieved my fever and malaria/typhoid pains to the monthly massaging has relieved some pains I used to feel and places the body correctly.

\section{(IDI/otakeme/oloibiri/20 I 8)}

From this participant, she also said that: I chose to use CAM because the medicines given to me in the hospital did not help me. Nevertheless, the TBAs woman instructed that I boil Agu and drink three times a day that I will find myself urinating, and this will ease the tightness and enable me to eat, and it happened like that. Using CAM has made me healthy physically because I can now eat well, and I do not feel pains anymore in my ribs. Also, massaging has enabled me to know how my baby is doing in my stomach because the baby now kicks fine and I'm happy.

\section{(IDI/otuakeme/oloibiri/20 | 8)}

From another participant from Otuokpoti, she narrated the benefits of using CAM and associated it with cultural belief. She further stated that because her friends were using it without any complaint, she began to use it as well. As she put it: "I prefer using CAM because of my cultural belief. My friends all use CAM, and they have not had any complaints. I believe that CAMs are more effective compared to conventional medicine. Besides, it is more affordable than conventional medicine. With N500 one can go and massage and get the local herbs at an affordable rate. Also, the plants' products and herbs are not difficult to find, and one can easily get them in our surrounding for free" (IDI/otuokpoti/anyama clan/2018).

Finally, while some of the participants associated the benefits of CAM to cultural belief, cost and its efficacy, others were of the view that it has spiritual benefits. As one of the participants interviewed from Otuoke explained cited the use of olive that when "olive oil is rubbed on my stomach along with prayers given by the pastor, that will make me not to go through early operation on my seventh-month pregnancy". Generally, the use of CAM has cultural, economic, physical and spiritual benefits to users.

\section{Perceived challenges/problems associated with the use of CAM}

(Table 4) examines the perceived problems associated with CAM use. As the table reveals, the mean of the construct 'lack of standardisation' is 3.21 while the standard deviation is 0.957 . From the preceding, it is acceptable that the lack of standardisation in the measurement of the quantities of CAMs to be taken by respondents could be a challenge to its uses. Moreover, again, with the calculated standard deviation showing small difference between the responses of respondents in the cohort suggests that the responses of the cohorts are not different from each other. This is to say, despite the benefits derived from the use of CAMs, when used without a standard rule of measurement, it could pose a threat to the users.

Furthermore, the mean of 'lack of research institutes on CAM' is 3.28 with a standard deviation of 0.686 . This also implies that this construct is acceptable as one of the perceived problems associated with the use of CAM even with a small difference between the cohorts of those that signified 'lack of research institutes' as a challenge of CAM use. This also serves as a pointer to the fact that the absence of research institutes on CAM could be disastrous to the users. Of course, the absence of research institutes on CAM may not allow for scientific investigations to the production, uses and efficacy of CAMs. If this is not addressed, it could endanger the health of the users.

In a similar vein, the mean of the construct of 'safety and precautions about CAM use' is 3.16 with a standard deviation of 0.823 . This is suggestive that the construct is acceptable as one of the perceived problems associated with the use of CAM even with small difference between responses of the cohorts 'safety and precautions about CAM use' as a challenge. In addition to this, the mean of the construct of 'too many quacks CAM practitioners' is 3.70, while the standard deviation is 0.946 . This construct also falls within the acceptable frame of perceived problems associated with the use of CAM, with the responses of those in the cohorts not being different from each other. These constructs are also pointers to the fact that when CAM is used without the awareness of its safety and precautions as well as availability of too many quacks practitioners, the health of many users could be aggravated instead of its purported improvement before the use of the CAM.

On the other hand, while the means of constructs above are acceptable as perceived problems associated with the use of 
CAMs, 'lack of laws and regulations' and 'inadequate training and certifications with the means of 2.89 and 2.96 respectively are rejected. The standard deviation of the construct of 'inadequate training and certifications' further reveals that there is a significant difference between the responses of those in the cohorts, as such, the responses are different from each other. These constructs point to the fact that they are not acceptable for the perceived problems associated with the use CAMs among the study population.

Table 4 Distribution of the respondents by perceived problems associated with CAM use $(n=325)$

\begin{tabular}{|c|c|c|c|c|c|c|c|c|}
\hline & \multirow[t]{2}{*}{$\begin{array}{l}\text { Problems associated with } \\
\text { CAM }\end{array}$} & \multicolumn{7}{|c|}{ 5-point Likert scale distribution } \\
\hline & & $\begin{array}{l}\text { Strongly } \\
\text { Disagree (\%) }\end{array}$ & Disagree (\%) & $\begin{array}{l}\text { Somewhat } \\
\text { Agree (\%) }\end{array}$ & Agree (\%) & $\begin{array}{l}\text { Strongly } \\
\text { Agree (\%) }\end{array}$ & $\begin{array}{l}\text { Mean } \\
\text { (Std. dev) }\end{array}$ & $\begin{array}{l}\text { Research } \\
\text { Decision }\end{array}$ \\
\hline 1 & Lack of standardization & - & $50(19.8)$ & $143(56.7)$ & $15(6.0)$ & $44(17.5)$ & $\begin{array}{l}3.21 \\
(0.957)\end{array}$ & Accept \\
\hline II & Lack of laws and regulations & $29(11.3)$ & $43(16.8)$ & $|2|(47.3)$ & $54(2 I . I)$ & $9(3.5)$ & $\begin{array}{l}2.89 \\
(0.982)\end{array}$ & Reject \\
\hline III & $\begin{array}{l}\text { Lack of research institutes on } \\
\text { CAM }\end{array}$ & - & $16(7.8)$ & $125(6 \mid .3)$ & $52(25.5)$ & I I (5.4) & $\begin{array}{l}3.28 \\
(0.686)\end{array}$ & Accept \\
\hline IV & $\begin{array}{l}\text { Lack of Safety and precautions } \\
\text { about CAM use }\end{array}$ & $4(1.8)$ & $35(15.6)$ & $122(54.2)$ & $50(22.2)$ & $14(6.2)$ & $\begin{array}{l}3.16 \\
(0.823)\end{array}$ & Accept \\
\hline V & $\begin{array}{l}\text { Inadequate training and } \\
\text { certifications }\end{array}$ & $52(20.3)$ & $10(3.9)$ & II 5 (44.9) & $54(2 I .1)$ & $25(9.8)$ & $\begin{array}{l}2.96 \\
(1.207)\end{array}$ & Reject \\
\hline VI & $\begin{array}{l}\text { Too many quacks CAM } \\
\text { practitioners }\end{array}$ & $2(0.9)$ & $10(4.5)$ & $100(45.2)$ & $50(22.6)$ & $59(26.7)$ & $\begin{array}{l}3.70 \\
(0.946)\end{array}$ & Accept \\
\hline
\end{tabular}

\section{Perceived risks associated with the use of CAM}

(Table 5) indicates perceived risks associated with the use of CAMs. While the means of constructs I, II, III, IV, and V are rejected as perceived dangers of CAM use, the mean of construct VI $(3.48 \pm 1.49)$ is accepted as perceived danger associated with the use CAMs. From the preceding, the risks of 'not a remedy for actual problem it was intended for', 'complications', 'serious side effects', 'difficult to ascertain dosage' and 'non-compatibility with conventional medicine' do not predispose pregnant women to health challenges when used.

However, the mean of construct VI is acceptable. This is because none of the CAMs is accepted to be scientifically proven before use while conventional medicines are always products of scientific investigations. For this reason, CAMs use may not be accepted as compatible with conventional medicine regardless of its perceived efficacy and cost-effectiveness. From the qualitative responses, however, different opinions about the perceived risks involved in the use of CAM were presented in themes.

Some participants thought that CAM use is risky. For instance, one of the participants viewed 'massaging' as one of the CAMs to be risky for the development of the foetus. As this participant explained, the traditional health practitioner may be ignorant of the side effects of massage, which ultimately affect the baby in the foetus after birth. In her statement: There are many risks involved in using CAM because most persons massaging may not know the side effects of CAM use. Some of our family members and friends that are suggesting alternative medicine are ignorant of the side effects that the CAM may bring to pregnant women. Again, most of the herbs used by pregnant women might affect the baby after birth. For example, I experienced some side effects of one herb that I used, because it was after sprinkling alligator pepper mixed with dry palm fronds that caused the sweety (rashes) all over my body" (IDI/otuoke/oloibiri/2018).
This implies that while the use of CAM may be beneficial to some users, it may not be beneficial to other users. However, the patterns of usage in terms of the timing, quantity and stage to which they can be used by pregnant women require investigation. This is because both orthodox and traditional medicine needs to be used appropriately. Moreover, when they are not used as prescribed either by the physicians or traditional healthcare providers, the adverse effects may not be palatable.

Many of the participants were of the opinions that there is no risk involved in the use of CAM. When participants were asked whether they use of CAM is risky or not, the emphasis was laid more on the benefits, rather than its side effects of CAM use. As this participant opined: I do not see any risks involved in using CAM. It is even a risk not to use CAM especially massaging because the mother will not know the position of the baby. Besides, the local herbs I used helped in relieving the pains I had because of the pregnancy. There are no risks involved in the dosage of CAM used. Just that it is not good to massage all the time, once a month is ok and only when the growing baby is matured in the womb. For the herbs, it does not matter the number of times you decide to take them; it does not become overdose. Instead, it makes the mother and child active and healthy (IDI/Otuasega/Agholo Clan/2018).

In support of this, this participant also stated that: Using CAM has been beneficial to me; the massaging enables me to know the position of my baby as well as relieve body pains. The alligator pepper and bitter kola enable me not to spit around as well as vomit. After taking the boiled vegetable leaf, my blood level improved (IDI/Otuokpoti/ Anyama Clan/2018).

Another participant is of the view that the use of CAM is beneficial at all times, except when there is an obstacle to its efficacy from witchcrafts. As the participant stated: I do not think there are any risks 
involved in using CAM, except when the pregnant woman did not listen to advice from the TBAs or maybe 'witch put hand' for me I feel CAM is safe; my mother has never regretted using CAM (IDI/ Otakeme/Oloibiri/2018).

From another participant who first felt that it was going to affect her when used, reluctantly used, and there was no experience of side effects. She narrated that: At first, when I was told to drink the herb, I was a little bit afraid, because I was wondering if it might harm my baby or me, or even worsen the pains. However, after taking the herbs for some days and felt relieved, better than the conventional medicines
I did not care or worry about any side effects or risks anymore (IDI/ Otuakeme/Oloibiri Clan/2018)

Generally, the use of CAM may be beneficial as well as involved risk. While most users of CAM may only see the benefits of its uses without its side effects, others may see and perceive that its side effects could be dangerous and pose threats to their health. In this, however, every medicine (modern or traditional), as beneficial it could be, there are also elements of side effects to some extent. If the side effects are not considered before the actual use, it may pose some threats to the health of the users.

Table 5 Distribution of the respondents by perceived risks associated with CAM use $(n=325)$

\begin{tabular}{|c|c|c|c|c|c|c|c|c|}
\hline & \multirow{2}{*}{$\begin{array}{l}\text { Perceived dangers of CAM } \\
\text { use }\end{array}$} & \multicolumn{7}{|c|}{ 5-point Likert scale distribution } \\
\hline & & $\begin{array}{l}\text { Strongly } \\
\text { Disagree (\%) }\end{array}$ & Disagree (\%) & $\begin{array}{l}\text { Somewhat } \\
\text { Agree (\%) }\end{array}$ & $\begin{array}{l}\text { Agree } \\
(\%)\end{array}$ & $\begin{array}{l}\text { Strongly } \\
\text { Agree (\%) }\end{array}$ & $\begin{array}{l}\text { Mean } \\
\text { (Std. dev) }\end{array}$ & $\begin{array}{l}\text { Research } \\
\text { Decision }\end{array}$ \\
\hline I & $\begin{array}{l}\text { It may not remedy the actual } \\
\text { problem it was intended for }\end{array}$ & $38(14.8)$ & $86(33.6)$ & $72(28.1)$ & $12(4.7)$ & $48(18.8)$ & $2.79(1.299)$ & Reject \\
\hline II & It may harm my unborn Child & $63(24.4)$ & $120(46.5)$ & $2 I(8.1)$ & $6(2.3)$ & $48(18.6)$ & $2.44(1.380)$ & Reject \\
\hline III & It may lead to complications & $36(15.3)$ & $119(50.6)$ & $28(11.9)$ & $10(4.3)$ & $42(17.9)$ & $2.59(1.309)$ & Reject \\
\hline IV & It may have serious sides effects & $66(26.7)$ & $77(31.2)$ & $44(17.8)$ & $18(7.3)$ & $42(17.0)$ & $2.57(1.398)$ & Reject \\
\hline V & $\begin{array}{l}\text { It may be difficult to ascertain } \\
\text { the exact quantity to consume }\end{array}$ & $44(19.2)$ & $24(10.5)$ & $105(45.9)$ & $22(9.6)$ & $34(14.8)$ & $2.90(1.249)$ & Reject \\
\hline $\mathrm{VI}$ & $\begin{array}{l}\text { It may not be compatible with } \\
\text { conventional medicine }\end{array}$ & $6(2.7)$ & $24(11.0)$ & $89(40.6)$ & $\begin{array}{l}59 \\
(26.9)\end{array}$ & $41(18.7)$ & $3.48(1.249)$ & Accept \\
\hline
\end{tabular}

\section{A multiple regression analysis showing the relationship between perceived benefits, problems, dangers, social network and extent of CAM use}

A multiple regression analysis was employed to determine the relationship between perceived benefits, problems, dangers and social networks that influence the extent of CAM use among pregnant women. This was informed by the need to take a wide-range understanding of the predictors of the extent of CAM use in Ogbia clan.

As (Table 6) shows the summary of the regression results in models I, II, and III, respectively, there is significant influence between predictor and dependent variables, which suggests that the explanatory variables significantly explained the dependent variable at higher percentages.

Model I however, the perceived benefits of CAM use and the dependent variable are significantly related $\left(\mathrm{R}=0.765, \mathrm{R}^{2}=0.585\right.$, $\mathrm{F}_{(5,81)}=22.837$, Adj. $\left.\mathrm{R}^{2}=0.559, \mathrm{p}<0.01\right)$. Among perceived benefits of CAM use variables, 'improved psychological/emotional wellbeing' independently contributed to the extent of CAM use among pregnant women by $39.7 \%$, while 'improved physical well-being and that of the baby' negatively influenced the use of CAM by $61.8 \%$, while remedy for pregnancy, boosted immune system and stabilizing health generally did not influence the extent of CAM use among pregnant women at this model. This is suggestive that there is more psychological influence of the use of CAM among pregnant women when compared to the medical aspect of its uses at model I. Considering the complex nature of the predictive influence of CAM use among pregnant women, variables of perceived problems of CAM use were included at model II. The combination of perceived benefits and problems of CAM use showed significant relationship with the dependent variable - extent of CAM use $\left(\mathrm{R}=0.0 .847, \mathrm{R}^{2}=0.718\right.$, $\mathrm{F}_{(11,75)}=17.381$, Adj. $\left.\mathrm{R}^{2}=0.677, \mathrm{p}<0.01\right)$.

Nonetheless, while remedy pregnancy discomfort, boosted immune system, stabilizes health generally, lack of standardization, lack of laws and regulations, including safety and precautions about CAM use and too many quack practitioners in alternative medicines did not determine the extent of CAM use among pregnant women; 'improved psychological/emotional well-being' independently influence the use of CAM by $35.1 \%$, followed by 'improved physical well-being and that of the baby' though with negative influence by $63.5 \%$. Despite the inclusion of variable 'lack of research institutes on CAM' in the model, the extent of CAM uses increased by $67.0 \%$, while 'inadequate training and certifications of CAM practitioners' had negative influence of $72.9 \%$ on CAM use.

In overall, there is an increase in the percentage of CAM use from $58.5 \%$ (Model I) to $67.7 \%$ (model II) despite the inclusion of the perceived problems associated with the extent of CAM use among pregnant women. This implies that the perceived problems of CAM use did not reduce the extent to which they are used by pregnant women.

Furthermore, while considerable concern has been given to perceived benefits and problems associated with the use of CAM at model II, model III was added to the regression analysis in order to examine the effects of perceived dangers of CAM use. The combination 
of perceived benefits, problems and dangers significantly influence the extent of CAM use among pregnant women $\left(\mathrm{R}=0.913, \mathrm{R}^{2}=0.834\right.$, $\mathrm{F}_{(17,69)}=20.360$, Adj. $\left.\mathrm{R}^{2}=0.793, \mathrm{p}<0.01\right)$. At this model, when variables of perceived dangers were included, some of the variables that were hitherto not independently found significantly influenced the extent of CAM use were now found independently significant. For example, 'remedy pregnancy discomfort' independently significantly determine the extent of CAM use among pregnant women though with negative influence by $20.8 \%$; 'stabilizes health generally' independently significantly influence the extent of CAM use $(\beta=-1.031, \mathrm{p}<0.05)$; as well as 'improved physical well-being of the mother's health and that of the baby' by $71.6 \%$ though with negative influence.

Similarly, 'lack of research institutes on CAM' had significant influence on the extent of CAM use $(\beta=1.387, p<0.05)$, 'safety and precautions about $\mathrm{CAM}$ use $(\beta=-0.771, \mathrm{p}<0.01)$, 'inadequate training and certifications of the practitioners' $(\beta=0.740, p<0.01)$, and 'too many quack practitioners' $(\beta=-0.939, p<0.01)$ respectively. The variables on perceived dangers of CAM use that are significantly related to the extent of CAM use include 'may lead to complication' $(\beta=-.673, p<0.05)$; 'may lead to serious side effects' $(\beta=-1.283$, $p<0.05)$ and 'difficult to ascertain quantity to consume' $(\beta=1.095$, $\mathrm{p}<0.05$ ). This means that when there are negative influences on some of the perceived dangers variables associated with the dependent variable, other variables had a positive influence on the extent of CAM us. This result showed that most respondents had not been adequately enlightened on the use of CAM in terms of the quantities, timing and patterns of its uses. This could be deduced from the fact that despite the 'inadequate training and certifications of the practitioners', there is still positive influence of the variable on the extent to which they use CAM. In other words, whether the practitioners are certified or not the users will continue to use CAM.

Table 6 Multiple regression analysis showing the relationship between perceived benefits, problems, risks, and extent of CAM use

\begin{tabular}{|c|c|c|c|c|c|c|c|c|c|}
\hline Model & Predictor Variables & F-Ratio & $\begin{array}{l}\text { Sig. } \\
\text { of } P\end{array}$ & $\mathbf{R}$ & $\mathbf{R}^{2}$ & Adj. $R^{2}$ & $\beta$ & $\mathbf{T}$ & P-value \\
\hline I & $\begin{array}{l}\text { Remedy pregnancy discomfort } \\
\text { Boosted immune system } \\
\text { Stabilises health generally } \\
\text { Improved psychological/emotional well-being } \\
\text { Improved physical well-being and that of the } \\
\text { baby }\end{array}$ & 22.837 & 0.000 & .765 & .585 & .559 & $\begin{array}{l}.020 \\
.372 \\
-.048 \\
.397 \\
-.618\end{array}$ & $\begin{array}{l}.231 \\
I .77 \mid \\
-.320 \\
3.552 \\
-6.148\end{array}$ & $\begin{array}{l}.818 \\
.080 \\
.750 \\
.001 \\
.000\end{array}$ \\
\hline II & $\begin{array}{l}\text { Remedy pregnancy discomfort } \\
\text { Boosted immune system } \\
\text { Stabilises health generally } \\
\text { Improved psychological/emotional well-being } \\
\text { Improved physical well-being and that of the } \\
\text { baby } \\
\text { Lack of standardisation } \\
\text { Lack of laws and regulations } \\
\text { Lack of research institutes on CAM } \\
\text { Safety and precautions about CAM use } \\
\text { Inadequate training and certifications } \\
\text { Too many quack practitioners }\end{array}$ & $|7.38|$ & 0.000 & .847 & .718 & .677 & $\begin{array}{l}-.069 \\
-.426 \\
.050 \\
.351 \\
-.635 \\
.487 \\
-.384 \\
.670 \\
.026 \\
-.729 \\
-.162\end{array}$ & $\begin{array}{l}-.775 \\
1.751 \\
.230 \\
3.058 \\
-6.588 \\
1.810 \\
-1.642 \\
2.369 \\
.174 \\
-4.453 \\
-1.404\end{array}$ & $\begin{array}{l}.441 \\
.084 \\
.819 \\
.003 \\
.000 \\
.074 \\
.105 \\
.020 \\
.863 \\
.000 \\
.164\end{array}$ \\
\hline III & $\begin{array}{l}\text { Remedy pregnancy discomfort } \\
\text { Boosted immune system } \\
\text { Stabilises health generally } \\
\text { Improved psychological/emotional well-being } \\
\text { Improved physical well-being and that of the } \\
\text { baby } \\
\text { Lack of standardisation } \\
\text { Lack of laws and regulations } \\
\text { Lack of research institutes on CAM } \\
\text { Safety and precautions about CAM use } \\
\text { Inadequate training and certifications } \\
\text { Too many quack practitioners } \\
\text { Not remedy the actual problem intended } \\
\text { May harm the unborn baby } \\
\text { May lead to complications } \\
\text { May lead to serious side effects } \\
\text { Difficult to ascertain quantity to consume } \\
\text { Not compatible with conventional medicine }\end{array}$ & 20.360 & 0.000 & .913 & .834 & .793 & $\begin{array}{l}-.208 \\
1.994 \\
-1.031 \\
-.133 \\
-.716 \\
-.211 \\
-.263 \\
1.387 \\
-.771 \\
.740 \\
-.939 \\
.372 \\
.784 \\
-.673 \\
-1.283 \\
1.095 \\
-.426\end{array}$ & $\begin{array}{l}-2.064 \\
1.697 \\
-2.171 \\
-.263 \\
-2.001 \\
-.525 \\
-.920 \\
3.190 \\
-4.020 \\
2.601 \\
-4.398 \\
.847 \\
1.069 \\
-2.409 \\
-5.027 \\
2.432 \\
-1.113\end{array}$ & $\begin{array}{l}.043 \\
.094 \\
.033 \\
.793 \\
.049 \\
.601 \\
.361 \\
.002 \\
.000 \\
.011 \\
.000 \\
.400 \\
.289 \\
.019 \\
.000 \\
.018 \\
.270\end{array}$ \\
\hline
\end{tabular}

Significant at $\mathrm{p} \leq 0.0 \mathrm{I}$ or 0.01 


\section{Discussion of findings}

The reasons for the use of CAM were examined in this study and to "relieve morning sickness during pregnancies" was the highest reason with a rate of $48.9 \%$. This result is quite different from that of Sawalha ${ }^{14}$ where it was discovered that "Abdominal pain" was the highest reason for the use of CAM among pregnant women (36.0\%). However, the finding of this study is similar with that of Orief et al., ${ }^{15}$ which discovered abdominal colic and Nausea/vomiting as the highest reasons for the use of CAM with a rate of $47.6 \%$; and $28.0 \%$; respectively. It is also similar to the study of Al-Riyami et al., ${ }^{16}$ which discovered "Flu and cold" as the highest reason for CAM use. The study discovered the reason/benefit for the use of CAM and majority of the respondent $32.1 \%$ strongly agreed with "Cultural belief" as a reason for the use of CAM, $57.6 \%$ agreed with "ease of access" as the main reason for the use of CAM and $48.2 \%$ also agreed with "easily affordable" as the main reason for the use of CAM. This finding is different from the study of Adawi., ${ }^{17}$ and Hashim et al., ${ }^{18}$ which discovered a high rate of $91.7 \%$ and $56.2 \%$ respectively, for "more effective than conventional medicine" and $82.5 \%$ and $52.4 \%$ respectively, for "less side effects than conventional medicine" as the main reason for the use of CAM. Nonetheless, the findings of this study are similar to that of Onyiapat et al.,$^{19}$ and Laelago et al., ${ }^{20}$ which discovered "easy access and affordability" as the primary reason for the use of CAM (44.6\%) and (41.1\%) respectively.

Again, this study discovered that most of the respondents did not perceive any risk associated with the use of CAM. A breakdown showed that $50 \%$ of the respondent disagreed that CAM may lead to complications, $46.5 \%$ disagreed that CAM may harm the unborn child, $33 \%$ of the respondent disagreed that it may not remedy the actual problem it was intended for, and 31\% disagreed that it may have any side effects. These findings correlate with that of Onyiapat et al. ${ }^{21}$ in which $66.8 \%$ of the respondent disagreed that CAM is harmful to both pregnant woman and the unborn child. Also, study conducted by Laelago et al., ${ }^{20}$ and (Okoronkwo et al., ${ }^{21}$ in which $91.1 \%$ and $70.3 \%$ of their respective respondent disagreed that CAM has any side effects after use.

\section{Conclusion and recommendations}

The use of CAM by pregnant women within the Niger Delta Region for its numerous benefits as perceived by the users is established in this study. Hence, its usage among pregnant women within the study area has gained recognition beyond the patronage of modern medicine since the use of CAM meets the needs of people who adhere and consumes it for health purposes. Based on the findings, the study concludes that the perceived predisposing factors that make pregnant women to patronise complementary and alternative medicine include: cultural beliefs, easy accessibility, meeting of primary health needs, easy affordability, spiritual potency, greater choices, control and participation, and emphasis on prevention and wellness. Additionally, non-availability of health centres, non-functional health centres, and challenges of health centres also contributes the pregnant women patronising CAM.

Furthermore, the study concludes that the pregnant women perceived the likely problem that might be associated with the use of CAM to include: Lack of standardisation, lack of research institutes on CAM, lack of Safety and precautions about CAM use, and too many quacks CAM practitioners. Similarly, pregnant women perceived that the only risk that might be associated with use of CAM is that it may not be compatible with conventional medicine. Hence, pregnant women do no perceive 'may not remedy the actual problem it was intended for, ' 'may harm my unborn Child,' 'may lead to complications,' 'may have serious sides effects,' and 'may be difficult to ascertain the exact quantity to consume' as possible risks that might be associated with CAM use. Finally, a combination of perceived benefits, problems, and risks does not lead to a reduction in the extent of CAM use. In other words, the perceived benefits lead to CAM use, perceived problems and risks still leads to CAM use.

Based on the findings from the study, it is recommended that community stakeholders, including pregnant women in the study location, be adequately oriented on the need to rely less on CAM and more on conventional medicine by Governmental and NonGovernmental agencies charged with the responsibility of ensuring the reduction of maternal and child mortality in the country. This is because most pregnant women strongly believe in the efficacy of the use of CAM even with the many flaws that have been identified by studies. Again, operations of TBA centres which fast been instituted in health practice, should be regulated and closely monitored by health services departments of the government in line with global best practices. TBAs practitioners should be licensed to separate the quacks from genuine practitioners. This will go a long way in ensuring women who prefer the use of TBAs are given health care that is not detrimental.

Additionally, the available health centres must be well-equipped with adequate maternal health facilities and human resources which are lacking especially in the rural areas. This has left pregnant women with no choice but to look for an alternative source of health care. Likewise, the current monthly financial inducement of N 3,000 for pregnant women who attend antenatal care in the city of Yenagoa, by the Bayelsa state government, should be emulated by other state Governors in the region and extended to the rural areas where the use of CAM is prevalent. Finally, the cost of health services for pregnant women should be significantly reduced (or made free if possible) by the government and private health centres. The enormous cost associated with patronising the hospital as discovered by the study was a significant factor that pushes pregnant women to use CAM which sometimes they get at very little or no cost.

\section{Author's contribution}

The whole research was conceived, deigned and analysed by E.Uzobo.

\section{Acknowledgments}

The author wish to appreciate the contributions by Prof. Edet M Abasiekong, who edited this work and made useful contributions to improve the status of this paper. We also acknowledge the contributions made by our research assistants: Miss Amakuro Nadiquan Doris, Miss Brightest Bright Inemugha, Miss Godswill Dumomaziba, and Miss Johnson Elizabeth who assisted in the process of data collection.

\section{Conflicts of interest}

The author declares that there are no conflicts of interest.

\section{Funding}

The author received no funding for this article. 


\section{References}

1. DeBoer H, Lamxay V. Plants Used During Pregnancy, Childbirth and Postpartum Healthcare in Lao PDR: A Comparative Study of Brou, Saek and Kry Ethnic Groups. Journal of Ethnobiology and Ethnomedicine. 2009;5:25.

2. Mupfumira R. An assessment of African Traditional Medicine in Pregnancy and on Birth Outcomes, Pharmacists' Perceptions of Complementary Medicines in Pregnancy. Grahamstown, South Africa: Rhodes University Press. 2012

3. Frenkel M, Ben Arye E, Carlson, C, et al. Integrating complementary and alternative medicine into conventional primary care: the patient perspective. Explore (New York). 2008;4(3):178-186.

4. Fakeye TO, Adisa R, Musa EI. Attitude and use of herbal medicines among pregnant women in Nigeria. BMC Complement. Alternat Med. 2009;9(10):53.

5. Westfall RE. Herbal healing in pregnancy: Women's experiences. Journal Herbal 2003;3(4):17-39.

6. Baccini M, Cuzzolin L, CamerlengoT, et al. Phytotherapeutic compounds. The consumer-pharmacist relationship. Drug Safety. 2008;31(5):424-427.

7. David MR, London ML, Ladewig PA. Maternal new-born nursing and women's health across the life span. New Jersey: Upper Saddle River. 2008 .

8. Braun L, Cohen M. Australian hospital pharmacists' attitudes, perceptions, knowledge and practices of CAMs. J Pharm Pract Res, 2007;37(3):220-223.

9. Mitchell M, Alen K. An exploratory study of women's experiences and key stake holders' view of Moxibustion for cephalic version in breech presentation. Complementary Therapies in Clinical Practice. 2008;14(4):264-272.

10. Harding D, Foureur M. New Zealand and Canadian Midwives' use of Complementary and Alternative Medicine. New Zealand College of Midwives Journal. 2009; 40:7-12.

11. World Health Organization. National Policy of Traditional and Complementary/Alternative Medicine; WHO Working Group Meeting on Integration of Traditional Medicine into National Health Systems; Geneva: 2006.
12. Chuntharapat S, Petpichetchian W, Hatthakit U. Yoga during pregnancy: Effects on maternal comfort, labour pain and birth outcomes. Complementary Therapies in Clinical Practice. 2008;14(2):105-115.

13. DeNicola E, Aburizaize OS, Siddique A, et al. Road Traffic Injury as a Major Public Health Issue in the Kingdom of Saudi Arabia: A Review. Frontiers in Public Health, 2016; 4(4);1-12.

14. Sawalha AF. Consumption of Prescription and non-Prescription Medications by Pregnant Women: A Cross-Sectional Study in Palestine. Islam Univ J. 2007;15(2):41-57.

15. Orief YI, Farghaly NF, Ibrahim MIA. Use of herbal medicines among pregnant women attending family health centres in Alexandria. Middle East Fertil Soc J. 2012;19(1):42-50.

16. Al Riyami, IM, Al Busaidy IQ, Al Zakwani IS. Medication use during pregnancy in Omani women. Int J Clin Pharm, 2011;33(4):634-641.

17. Adawi DH. Prevalence and Predictors of Herb Use during Pregnancy (A study at Rafidia Governmental Hospital/ Palestine). 2012.

18. Hashim M, Johina A, Deyaa K, et al. Knowledge attitude and practice of complementary and alternative medicine (CAM) among preg n a n women: a preliminary survey in Qatar. Middle East J Fam Med. 2005;7(10):6-19.

19. Onyiapat JE, Okoronkwo IL, Ogbonnaya NP. Complementary and alternative medicine use among adults in Enugu, Nigeria. BMC Complementary and Alternative Medicine. 2011;11(1):19.

20. Laelago T, Yohannes T, Fiseha F. Prevalence of herbal medicine use and associated factors among pregnant women attending antenatal care at public health facilities in Hossana Town, Southern Ethiopia: facility based cross sectional study. Archives of Public Health. 2016;74(7):1-8.

21. Okoronkwo I, Onyia-pat J, Okpala P, et al. Patterns of Complementary and Alternative Medicine Use, Perceived Benefits, and Adverse Effects among Adult Users in Enugu Urban, Southeast Nigeria. Evidence-Based Complementary and Alternative Medicine. 2014;1-6. 